\title{
SEX AS A SOURCE OF HETEROGENEITY IN A MENTAL HEALTH SURVEY
}

\author{
Monica D. Blumenthal \\ Mental Health Research Institute, University of Michigan, Ann Arbor, Michigan 48104
}

(Received 1 June 1966)

(Revised 9 December 1966)

WE HAVE recently conducted a field study evaluating the relative mental health of three small populations. In spite of the fact that this investigation was not conceived as an epidemiologic study, it became necessary for us to contend with some of the problems which have plagued studies of psychiatric epidemiology in the past. The most pressing of these difficulties relates to the lack of reliability of psychiatric diagnosis and the consequent uncertainty about designating a person in a community as a 'psychiatric case'. 'This lack of reliability is well known and has been reviwed by BLUM. ${ }^{1}$ In addition, we were unable to find a generally accepted, validated instrument which could substitute for psychiatric diagnosis in a field study. This placed us in the predicament of having no criterion available which would give us reliable, valid measures of psychiatric illness. This situation has been discussed by CRONBACH and MEEHL" who suggest that "construct validity must be investigated whenever no criterion or universe of content is accepted as entirely adequate to define the quality to be measured".

Construct validity is a concept applicable when a test is interpreted as a measure of an attribute which cannot be operationally defined. Such a construct should contain statements which lead to predictable relationships with observable phenomena. Since we were not attempting to estimate the incidence of psychiatric diseases, but only to measure the relative mental health of three groups, the use of such concepts seemed reasonable. A series of constructs were developed, the mental health indices, which were regarded as measures of mental illness. These indices were based on concrete questions which had some obvious face validity. In order to relate these constructs to observable measures, the relationship between the indices and visits to physicians and hospitalizations for mental health problems was determined by a correlational analysis. Such visits and hospitalizations could theoretically be validated by independent data. These events also represent phenomena which most observers will agree are probably quite closely related to mental illness. Such correlations give some estimate of the validity of the measures.

The results of this analysis demonstrated that relationships between constructs were often significantly different for the two sexes. Constructs might show a high degree of validity, in terms of relationship to hospitalization, for one sex without showing comparable validity for the other. The presence of two sexes in the population investigated can be regarded as an example of unlike, or heterogeneous, subgroups within a population. This situation occurs 
often in psychiatric investigation, and it is likely that in much psychiatric rescarch the investigator may be dealing with a heterogeneous population consisting of numerous subgroups. ${ }^{3,4}$

Since factors producing heterogeneity in psychiatric research are often unknown and consequently difficult to control, it seems reasonable to explore the effects of heterogeneity on a data analysis. When the two sexes are used as an example of heterogeneous subgroups within a population, our results provide some insight into statistical and inferential errors that may occur in data analysis of non-homogeneous populations.

\section{METHOD}

The subjects investigated consisted of the parents of three groups of children; sixty-four with phenylketonuria (PKU), sixty-four with non-phenylketonuric mental retardation (NPMR), and sixty-four with cystic fibrosis (CF). A more detailed description of the sample has been reported elsewhere. ${ }^{5}$ These parents were investigated by means of a standard structured interview schedule, and were interviewed by professional interviewers. The interview was coded by highly explicit coding procedures by a professional coding staff. The interview was repetitive in nature and problems relevant to specific mental health areas could appear in more than one place, so that it was essential to assemble data related to single topics. A series of mental health indices were devised for this purpose. Indices were primarily based on a single line of questioning concerning one potential problem area. Arbitrary units were assigned to positive answers; most often the unit was one, but higher units would be assigned if it seemed warranted. In general, higher units were assigned only to behavior which could be taken as a definite sign of psychiatric disturbance. For example in the Depression Index (Table 1) the respondent would receive one point for feeling that life was not worth living, two for seeking medical help for depressive problems, and three for a suicide attempt. All indices were checked against other questions in the interview where relevant information might appear. For example, the Depression Index was constructed so that information about suicide attempts, depressions, etc. which had been elicited by open-ended questions dealing with nervous breakdown or divorce, could be transferred to add to the score for the Depression Index. The total number of points was a sum of parts. For a given individual, higher scores indicated a larger number of problems, or problems of a more serious nature, while mean scores for a group within the population might indicate either that the same proportion of individuals had reported more serious problems, or that a larger number of individuals had reported similar problems. On the whole, these indices were as concrete and unintuitive as we could make them. Tables 1-7 show how the indices were scored, and the main line of questioning in the interview from which they were derived. The indices covered drinking problems (Alcohol Index), suicides and depressions (Depression Index), perceived nervous brcakdowns (Nervous Breakdown Index), a symptom check list (Mental Health Score), visits to physicians for mental health problems (Professional Persons Index), and hospitalizations for mental health reasons (Hospitalizations Index). As far as we know questions contributing to the Alcohol Index, Depression Index, Professional Persons Index, and Hospitalizations Index, are unique to this study. The question about nervous breakdowns was originally taken from GURIN, VEROFF and FELD. ${ }^{\dagger}$ 
The Mcntal Health Score (Tables 3 and 4) differed substantially from the other indices in several respects. This index consisted of a set of twenty-two questions which have been repeatedly used in other studies of psychiatric epidemiology. These questions are heavily loaded towards the somatic, towards depressive symptomatology, and towards symptoms generally associated with anxiety. The questions were originally selected by LANGNER ${ }^{7}$ for their ability to discriminate between psychiatrically 'ill' and 'well' populations. Items in the Score have less obvious face validity than most of the items of our other indices; nevertheless, this Score is the only one of our indices which has been the subject of a validity study. It has been demonstrated by a field study, that the Score could differentiate between patients in an admitting ward of a mental hospital and persons in community populations. In addition, scores correlated with clinical assessments of patients by ward personnel. ${ }^{8}$

TABLE 1. DEPRESSION INDEX

QUESTIONS

\footnotetext{
"People are sometimes troubled by depressions or sadness. At those times they may lose interest in things, have troublc working, and feel that they are not as good as they should be. Have you ever been so sad or low in spirits that you couldn't do things you wanted to do?"; Yes, No.

"Have you ever felt so bad that you felt life wasn't worth living?"; Yes, No.

"Did you ever think or talk about taking your own life?"; Yes, No.

"What was that about? How old were you?"

"Did this have to do with anything going on in your family?"

"Have you ever tried to end your life?"; Yes, No.

"What happened?"

"How old were you?"

"Did you get any special help or go to a doctor or a hospital at that time (for either thinking about or attempting to take your own life)?"; Yes, No.

"Who helped you? (Name and title of doctor, if given) Where was that? (Name of hospital, clinic, etc., city and state) What month and year was that ? Date of last contact (Month, Year)."
}

\section{SCORING}

\begin{tabular}{lrr}
\hline \multicolumn{1}{c}{ Item } & \multicolumn{2}{c}{ Score } \\
\cline { 2 - 3 } & No & Yes \\
\hline $\begin{array}{l}\text { Could not do things because of low spirits } \\
\text { Felt life wasn't worth living }\end{array}$ & 0 & 1 \\
Thought or spoke of taking own life & 0 & 1 \\
Tried to take own life & 0 & 1 \\
Went to hospital or doctor for thinking or attempting to take own life & 0 & 3 \\
$\begin{array}{l}\text { Spontaneous mention of depression, crying spells, or loss of interest in usual } \\
\text { activities in open-ended code (may occur at five locations) }\end{array}$ & 0 & 2 \\
\hline Highest possible total for depression & 0 & 1 \\
& & 11 \\
\hline
\end{tabular}


TABle 2. AlCOHOL INDEX

\section{QUESTIONS}

"Drinking is another health area which is very important for us to know about. Please tell me, how often do you drink any beer or wine or liquor?"; Nearly every day, Once or twice a week, Less often than once a week, Never.

"Did you ever in your life occasionally drink any beer or wine or liquor?"; Yes, No. Never drank at all.

"Did you ever feel that you drank more than you should have?"; Yes, No.

"Has your drinking ever caused any problem in your daily work or in your family?"; Yes, No.

"Like What?"

"Did it ever affect your health in any way?"; Yes, No. Comments:

"Did you ever go to a hospital or clinic for any reason having to do with drinking?"; Yes, No.

"Where did you go to? (Name of hospital or clinic) What city and state is that ?" (City and state) when was the last time? Date of last contact (Month, Year)."

\section{SCORING}

Items related to drinking

Score

\begin{tabular}{|c|c|c|}
\hline $\begin{array}{l}\text { Frequency } \\
\text { of } \\
\text { Drinking }\end{array}$ & $\begin{array}{l}\text { Never or never 'too much' } \\
\text { Every now and then } \\
\text { Often or all the time }\end{array}$ & $\begin{array}{l}0 \\
1 \\
2\end{array}$ \\
\hline $\begin{array}{l}\text { Work- } \\
\text { Related } \\
\text { Problems }\end{array}$ & $\begin{array}{l}\text { None } \\
\text { Some: unspecified; occasional absence from work, housework and child care } \\
\text { suffers } \\
\text { Some: loss of job or business, other large financial loss, or does not work } \\
\text { because of drinking }\end{array}$ & $\begin{array}{l}0 \\
1 \\
2\end{array}$ \\
\hline $\begin{array}{l}\text { Marital } \\
\text { Problems }\end{array}$ & $\begin{array}{l}\text { None } \\
\text { Some: unspecified; disapproval of spouse, or arguments with spouse or } \\
\text { child(ren) } \\
\text { Some: separation or divorce because of drinking. }\end{array}$ & $\begin{array}{l}0 \\
1 \\
2\end{array}$ \\
\hline $\begin{array}{l}\text { Health } \\
\text { Problems }\end{array}$ & $\begin{array}{l}\text { None } \\
\text { Health problem not due to but made worse by drinking } \\
\text { Health problcm dircetly duc to alcohol: gastritis, cirrhosis pancreatitis, etc., } \\
\text { or accident suffered while drunk }\end{array}$ & $\begin{array}{l}0 \\
1 \\
2\end{array}$ \\
\hline
\end{tabular}

\begin{tabular}{lll}
\hline Legal & No mcntion & $\mathbf{0}$ \\
Problems & Tickets received due to drinking & $\mathbf{1}$
\end{tabular}

Drunk and disorderly charges, jailed for drinking or for felony committed while drunk 2

Hospital Has not gone for drinking problem 0

or Clinic Has gone for drinking problem 1

Highest possible total for alcohol-related problems 
Table 3. Mfental Hfat,th Score

QUESTIONS

"Are you ever troubled with headaches?"; Often, Sometimes, Never.

"Do you ever have any trouble in getting to sleep or staying asleep?"; Often, Sometimes, Never.

"Do your hands ever tremble enough to bother you?"; Often, Sometimes, Never.

"Have you ever been bothered by shortness of breath when you were not exercising or working hard ?"; Often, Sometimes, Never.

"Have you ever been bothered by 'cold sweats'?"; Often, Sometimes, Never.

"Have you ever been bothered by your heart beating hard?"; Often, Sometimes, Never.

"Are you ever bothered by nervousness (feeling irritable, fidgety, tense)?"; Often, Sometimes, Never.

"Have you ever had any fainting spells?"; Often, A few times, More than a few times.

"How would you describe your appetite?"; Poor, Fair, Good, Very Good.

"In general, would you say that most of the time you are in; High spirits, Good spirits, Low spirits, Very low spirits?"

I am the worrying type; Yes, No.

I feel somewhat apart even among friends; Yes, No.

I feel weak all over much of the time; Yes, No.

I have periods of such restlessness that I cannot sit long in a chair; Yes, No.

I am bothered by acid (sour) stomach several times a week; Yes, No.

My memory seems to be all right; Yes, No.

Every so often I suddenly feel hot all over; Yes, No.

I have had periods of days, weeks, or months when I couldn't 'get going'; Yes, No.

There seems to be a fullness (clogging) in my head or nose much of the time; Yes, No.

Nothing ever turns out for me the way I want it to; True for me, Not true for me.

I have personal worries that get me down physically; Yes, No.

I sometimes can't help wondering whether anything is worthwhile anymore: True for me, Not true for me."

Table 4. Mental Health Score

SCORING

\begin{tabular}{lcc}
\hline & \multicolumn{2}{c}{ Score } \\
\cline { 2 - 3 } & No & Yes \\
\hline Headaches, often & 0 & 1 \\
Trouble sleeping, often & 0 & 1 \\
Hands tremble, often & 0 & 1 \\
Shortness of breath, often & 0 & 1 \\
Cold sweats, often & 0 & 1 \\
Heart beating hard, often & 0 & 1 \\
Nervousness, often & 0 & 1 \\
Fainting spells, more than a few times & 0 & 1 \\
Appetite, poor & 0 & 1 \\
Spirits, low or very low & 0 & 1 \\
Worrying type & 0 & 1 \\
Feel apart & 0 & 1 \\
Wcak all over & 0 & 1 \\
Restlessness & 0 & 1 \\
Acid stomach & 0 & 1 \\
Memory problem & 0 & 1 \\
Hot all over & 0 & 1 \\
Couldn't get going & 0 & 1 \\
Fullness in head & 0 & 1 \\
Nothing turns out for me & 0 & 1 \\
Personal worries & 0 & 1 \\
Wonder if anything is worthwhile & 0 & 1 \\
\hline Highest possible for Mental Health Score & & $\mathbf{2 2}$ \\
\hline
\end{tabular}


TARLE 5. NERVOUS BREAKDOWN INDEX QUESTIONS

"Did this whole situation about (child) ever make you feel that you might have a nervous breakdown?"; Yes, No.

"Can you tell me (more about) how you felt at that time?"

"Did you ever get any special help or treatment for your (being upset or nervous)?"; Yes, No.

"Whom did you see? (Title of person or name) Where was that? (Name of hospital/clinic; city and state) When was that?" (Month and year).

"Have you ever felt that you were going to have a nervous breakdown (not including the strain because of (child))?"; Yes, No.

"Could you tell me what that was about?"

"How old were you when that happened?"

"Did you ever go to a doctor for this?"; Yes, No.

"What kind of doctor was this?" (Speciality)

"Did you visit a clinic or hospital for this?"; Yes, No, Don't know.

"What was the name of hospital/clinic? Where is that? (City and state) When was that?" (Month and year)."

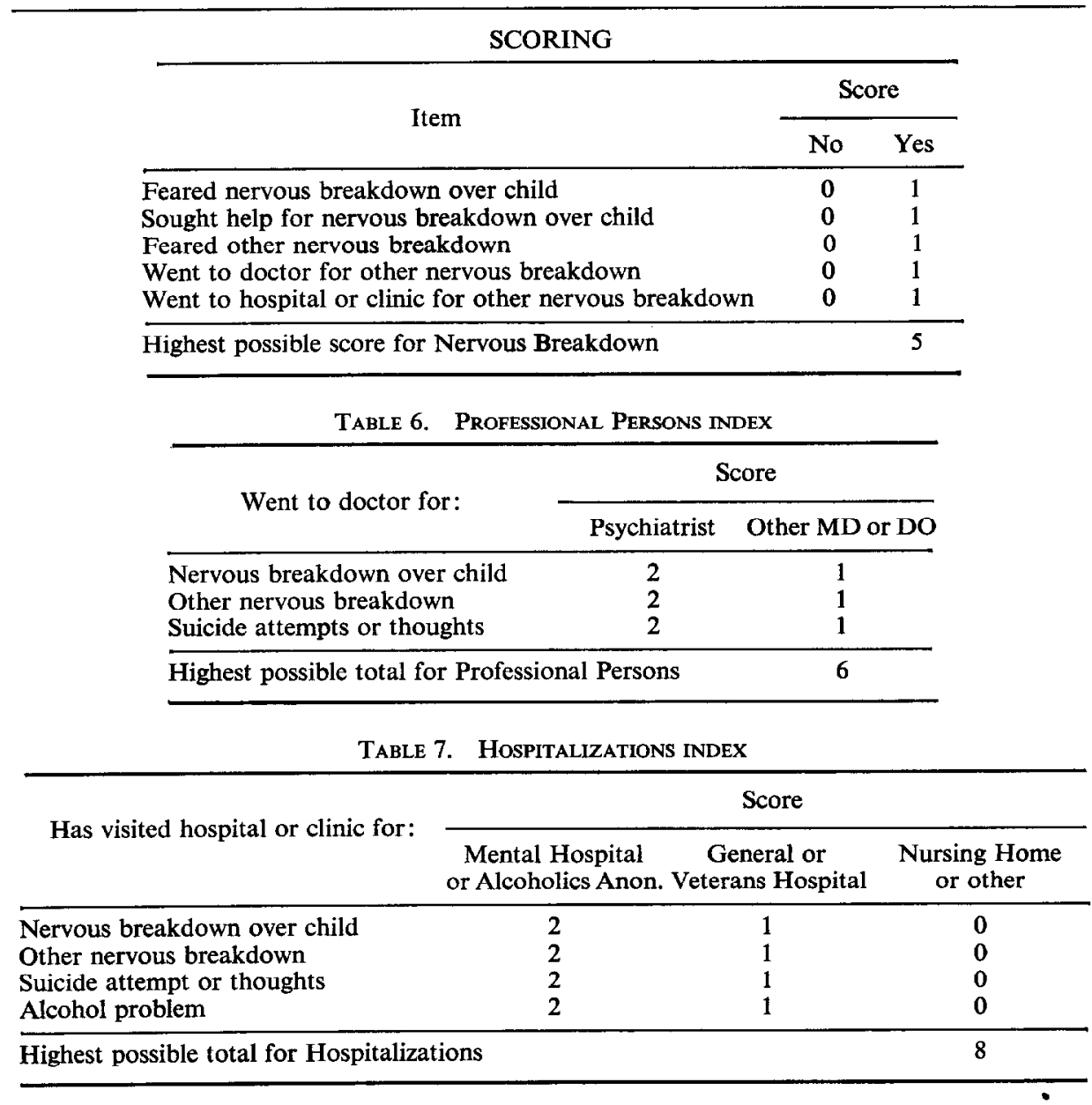


The method used in the correlational analysis was computed according to a program by HALl and CrAmer. ${ }^{9}$ These correlations are error correlations which are not computed over the data as a whole, but are mean correlations which result from averaging correlations between two variables in each cell of an analysis of variance matrix. Sex, social class, and population group (PKU, NPMR, and CF) determine the cells. All correlations represent the averages of correlations computed for mothers of PKU children in Social Class I, mothers of PKU children in Social Class II, mothers of PKU children in Social Class III, fathers of PKU children in Social Class I, etc. The net effect of such an analysis is to remove any correlation between two variables which is only a function of a third variable. For example, if two variables which tend to increase with decreasing social class are not related to each other in any other way, no significant error correlation would be obtained, although conventional correlations might very well show significant results. The significance of the difference between correlations was calculated according to HAYs. ${ }^{10}$

\section{RESULTS}

A large number of significant correlations appeared between the mental health indices. Some of these had been anticipated since they were more or less built into either the interview schedule or the indices; others were not. The 'built in' nature of some of these correlations can best be demonstrated by the relationship of the Hospitalizations Index to the other indices. It can be seen in Table 7 that scores on the Hospitalizations Index represent hospitalizations for mental health problems. However, the respondent was never asked about such a hospitalization unless a positive response was elicited by questions about a specific problem area such as perceived nervous breakdowns, depressions, or drinking problems. It follows that the Hospitalizations Index must be correlated with at least some of the indices derived from these lines of inquiry. An additional factor contributing to the 'built in' nature of these correlations is that most of the indices allow one or two points for seeking medical care or hospitalization for that condition.

Inspection of the relationships between the Hospitalizations Index and the other indices (Table 8) shows the Nervous Breakdown Index to be most highly correlated. The next highest correlation is with the Professional Persons Index, followed by unimpressive but

TABLE 8. CoRrelations between mental health indices

\begin{tabular}{|c|c|c|c|c|c|}
\hline Index & $\begin{array}{c}\text { Mental } \\
\text { Health } \\
\text { Score }\end{array}$ & $\begin{array}{c}\text { Nervous } \\
\text { Breakdown }\end{array}$ & Depression & $\begin{array}{l}\text { Professional } \\
\text { Persons }\end{array}$ & Alcohol \\
\hline Hospitalizations & $0 \cdot 11$ & $0.48 \dagger$ & $0 \cdot 18 \dagger$ & $0.40 \dagger$ & 0.06 \\
\hline Mental Health Score & - & $0 \cdot 16^{*}$ & $0 \cdot 15^{*}$ & $0 \cdot 14^{*}$ & $0 \cdot 11$ \\
\hline Nervous Breakdown & - & - & $0 \cdot 31 \dagger$ & $0.77 \dagger$ & $0 \cdot 14^{*}$ \\
\hline Depression & - & - & - & $0.28 \dagger$ & $0 \cdot 13$ \\
\hline Professional Persons & - & - & - & 一 & $0 \cdot 10$ \\
\hline
\end{tabular}

Number $=331$.

* Significant at the 5\% level of confidence.

$\dagger$ Significant at the $1 \%$ level of confidence. 
significant relationships with the Depression Index and the Mental Health Score. Interestingly enough, there was no significant correlation with the Alcohol Index, in spite of the fact that this line of questions presented the respondent with a similar opportunity to report hospitalizations.

When men and women are considered separately and error correlations between the Hospitalizations Index and the other mental health indices are computed independently (Table 9) a number of discrepancies appear. The Hospitalizations Index has a higher

TABle 9. Correlations BETWEEN THE HosPitAlizations INDEX AND OTHER MENTAL HEALTH INDICES FOR MEN AND WOMEN

\begin{tabular}{llll}
\hline \multicolumn{1}{c}{ Index } & Men & Women & $P \dagger$ \\
\hline Number & 158 & 173 & - \\
Alcohol & 0.08 & 0.03 & - \\
Mental Health Score & $0 \cdot 31^{*}$ & $0 \cdot 08$ & $5 \%$ \\
Professional Persons & $0 \cdot 32^{*}$ & $0 \cdot 52^{*}$ & $1 \%$ \\
Depression & 0.07 & $0 \cdot 30^{*}$ & $1 \%$ \\
Nervous Breakdown & $0 \cdot 64^{*}$ & $0.35^{*}$ & $0 \cdot 1 \%$ \\
\hline
\end{tabular}

* Significant at the $1 \%$ level of confidence.

$\dagger$ Level of confidence that correlations for men and women are significantly different.

correlation with the Mental Health Score for men than for the combined population, while women show no significant correlation between these two indices. Women, on the other hand, show a significantly larger correlation between the Depression Index and the Hospitalizations Index than men, for whom this relationship is insignificant. In every case, where there is a significant correlation between the Hospitalizations Index and one of the other mental health indices for the whole population, the correlations for women are significantly different from those calculated for men. This difference is most impressive for the correlation with the Nervous Breakdown Index; for women this correlation accounts

Table 10. MEAN SCORES OF MENTAL HEALTH INDiCES FOR MEN AND WOMEN*

\begin{tabular}{llc}
\hline \multicolumn{1}{c}{ Index } & Men & Women \\
\hline Number & 158 & 173 \\
Alcohol & 0.54 & $0.17 \ddagger$ \\
Mental Health Score & 2.13 & $3.36 \dagger$ \\
Professional Persons & 0.17 & $0.36 \dagger$ \\
Hospitalizations & 0.08 & 0.08 \\
Depression & 0.52 & $1.07 \ddagger$ \\
Nervous Breakdown & 0.40 & $0.77 \dagger$ \\
\hline
\end{tabular}

* Significance of the differences computed according to analysis of variance programmed by HALL and CRAMER. ${ }^{9}$

$\uparrow$ Differs from men at the $1 \%$ level of confidence.

$\ddagger$ Differs from men at the $0.1 \%$ level of confidence. 
for $12 \cdot 2$ per cent of the variance associated with hospitalizations, while for men the correlation accounts for $41 \cdot 1$ per cent of this variance.

These sex-related differences in the correlations of the indices could not have been predicted from differences between mean values. Table 10 shows the mean indices for men and women, the latter scoring higher on all indices except Alcohol and Hospitalizations. Certainly, there is nothing about these values per se which necessitates the observed differences in correlation.

The relationship of the Mental Health Score to the other indices is somewhat different from those previously discussed. Unlike our other indices, the Score is composed of questions which have no obvious relationship to any particular mental health problem. There are no overlapping questions with the other indices, and there was nothing about the mechanics of the interview schedule which required the appearance of any correlations. However, a number of such correlations do exist (Table 8).

For the whole population, the signiticant correlations between the Mental Health Score and the other indices are very small. When the same correlations are calculated for the data derived from women only, we find that none reach significance. But, when the correlations are calculated from data derived from men, the correlations become substantially larger than those which appear for the combined population (Table 11). In addition, men show

Table 11. Correlations between the Mental Health Score and other MENTAL HEALTH INUICES FOR MEN AND WOMEN

\begin{tabular}{llcc}
\hline \multicolumn{1}{c}{ Index } & Men & Women & $P^{*}$ \\
\hline Number & 158 & 173 & - \\
Alcohol & $0.29 \dagger$ & 0.08 & $5 \%$ \\
Professional Persons & $0 \cdot 33 \dagger$ & $0 \cdot 11$ & $5 \%$ \\
Hospitalizations & $0 \cdot 31 \dagger$ & 0.08 & $5 \%$ \\
Depression & $0.45 \dagger$ & $0 \cdot 11$ & $0 \cdot 1 \%$ \\
Nervous Breakdown & $0.41 \dagger$ & 0.12 & $1 \%$ \\
\hline
\end{tabular}

* Level of confidence that correlations for men and women are significantly different.

$\uparrow$ Significant at the $1 \%$ level of confidence.

significant correlations between the Mental Health Score and the Alcohol and Hospitalizations Indices, which had not reached minimal significance for the whole population. In every case, the correlations between the Mental Health Score and the other indices are significantly greater for men than for women.

Since the complaints evaluated by the Mental Health Score so frequently appear in association with clinical psychiatric disorders, it seemed unlikely that there was truly no relationship between this Score and the other indices for women. It seemed reasonable that women might also represent a heterogeneous population, composed of those whose complaints were related to mental health problems, and those who perceived themselves as having no mental health problems but who were 'complainers'. To test this hypothesis, correlations were obtained between indices on only those members of the population who 
had scored positively on at least one mental health index other than the Mental Health Score (Table 12).

Table 12. Correlations between the Mental Health Score and other INDICES FOR PERSONS SCORING POSITIVELY ON ONE OR MORE INDICES

\begin{tabular}{llcc}
\hline \multicolumn{1}{c}{ Index } & Total & Male & Female \\
\hline Number & 203 & 90 & 113 \\
Alcoholism & $0 \cdot 20^{*}$ & $0 \cdot 18$ & $0 \cdot 24^{*}$ \\
Professional Persons & $0 \cdot 26 \dagger$ & $0 \cdot 27^{*}$ & $0 \cdot 26 \dagger$ \\
Hospitalizations & $0 \cdot 23^{*}$ & $0 \cdot 29 \dagger$ & $0 \cdot 18$ \\
Depression & $0 \cdot 32 \dagger$ & $0 \cdot 37 \dagger$ & $0 \cdot 29 \dagger$ \\
Nervous Breakdown & $0 \cdot 34 \dagger$ & $0.35 \dagger$ & $0 \cdot 33 \dagger$ \\
\hline
\end{tabular}

* Significant at the $5 \%$ level of confidence.

+ Significant at the $1 \%$ level of confidence.

It can be seen that when those not scoring on indices other than the Mental Health Score are removed from the population, women show significant correlations between the Mental Health Score and the other indices. Interestingly enough, when the men not scoring on other mental health indices are removed from the group, correlations between the Mental Health Score and the other indices are reduced. This indicates that, unlike women, men not scoring on the mental health indices are not likely to make high scores on the Mental Health Score. Such a reduction in correlation indicates that men form a more homogeneous group.

\section{DISCUSSION}

We have presented a set of constructs used as measures of mental illness in a field study. These constructs had the advantage of specifying relatively clearly what areas were investigated, of lending themselves easily to computer analysis, of being reliably assigned, and of circumventing the necessity of making a psychiatric diagnosis on a person in a community. A major problem with these constructs is that they do not have the validity of a psychiatric opinion. The importance of this lack of validation should not be underestimated; psychiatric opinion is by definition the ultimate criterion by which mental illness is measured. Unfortunately, lack of reliability in psychiatric diagnosis creates serious difficulties in the application of this criterion to other measures of mental illness. ${ }^{1}$

The fact that the indices correlated with such concrete measures of mental illness as visits to physicians and hospitalizations for mental illness gives these measures a certain validity. It should be pointed out that this is only an internal validity, that is, since both measures are derived from the same interview, the data indicate only the extent to which the respondents perceived the questions as related to serious mental health problems. They do not give information about how much mental illness was forgotten or deliberately under-reported by the respondents. Since the original object of the study was to compare the relative mental health of three groups, the lack of external validation can be minimized if it is assumed that the extent of under-reporting was the same in all groups. 
Corrclations between indices showed a number of interesting characteristics which are related to the differences between men and women in our population. Correlations between the Mental Health Score and the other indices were highly significant for men and not at all significant for women. Over 65 per cent of the variance of the Mental Health Score can be accounted for in terms of correlations with indices representing concrete questions about mental illness for men, while almost none of the variance of this score for women is associated with other indices. This is not a surprising finding when one considers cultural differences in the roles assigned to men and women. Men are expected to bear their troubles silently while women are allowed to complain. When a woman weeps or has a headache or says she isn't feeling well, she is behaving within a culturally accepted framework, while a man using the same behaviors is not. It seems logical, that when a man makes similar complaints on a symptom check list, such complaints are indicative of more serious problems than those of women.

Our data indicate that the Mental Health Score is a more useful measure of mental illness for men in our population and that it is unreasonable to equate numerical scores for the two sexes. One of the interesting characteristics of these findings is that if only data for the whole population had been available, the meaningful relationship between the Score and other mental health indices for men whould have been overlooked. Not only were the correlations for the whole group very small; the relationship between drinking problems, hospitalizations, and the Score become altogether insignificant. This can be regarded as an example of a heterogeneous element in the population creating such statistical noise that a relationship which is meaningful for a subgroup disappears or becomes trivial when the relationship is examined in the whole population. This seems surprising and somewhat painful when one considers that the men in our population are about half the group.

Another example of how heterogeneous subgroups can change the apparent interpretation of a relationship can be seen in the relationship between the Nervous Breakdown and Hospitalizations Indices. For the whole population, these indices show a moderate correlation which would lead one to conclude that nervous breakdowns represent serious events to the respondents. Further analysis shows that the correlation is much higher for men than for women, i.e. there is a much higher likelihood that a man who reports a nervous breakdown will be hospitalized for an emotional problem than a woman. It follows that a man in our population must view a nervous breakdown as a more serious problem than a woman, or that he finds himself less able to cope with the problem without disrupting his ordinary routine, or that he reports it only when the problem has reached more serious dimensions. If a positive response to the nervous breakdown question does not mean the same thing to men as to women, then it follows that it is not possible to compare mental health in these two groups simply by measuring the relative number of positive responses. It is also true, that since we have used correlation with hospitalization as a measure of validity that the Nervous Breakdown Index has a different validity for the two sexes. It follows that the original interpretation of the correlation for the whole population must be modified to include two non-equivalent relationships which cannot reasonably be explained by the same statement.

Sex is an obvious source of heterogeneity and has been discussed by many workers. WITTENBORN and SMITH ${ }^{11,12}$ find that symptom patterns manifested by female chronic 
mental patients differ from those of males. LEIGHTON et al., ${ }^{13}$ find a larger number of symptom patterns among women than men in a study of psychiatric disorder in a Canadian community, while GURIN, VerofF, and FELD ${ }^{6}$ show many sex-related differences in their mental health study of a nationwide sample. There are many sources of heterogeneity in psychiatric studies, some of which are unknown. It seems reasonable to suppose that any source of heterogeneity would produce effects similar to those produced by sex in these data, i.e. the diminution or loss of meaningful relationships on the one hand, and errors in interpretation on the other. The finding that one segment of a population can actually create enough statistical noise to obscure a relationship which is meaningful for another large segment would appear to present a very serious problem in data analysis, especially in cases where the source of the heterogeneity is unidentified.

\section{SUMMARY}

We have presented a series of constructs which were developed to measure the relative mental health of the members of three small populations. These constructs were highly concrete, and each of the 331 respondents investigated could be assigned a numerical rating without the use of clinical judgements of trained personnel. These constructs proved to be intercorrelated to a large degree. It was demonstrated that the size of the correlation between constructs was not always an accurate reflection of relationships within the population, so that certain relationships which were highly significant for men proved to be insignificant for women, and vice versa. The heterogeneous nature of the population could be shown to lead to two kinds of errors when data was looked at only for the population as a whole. (1) Loss or diminution of relationships which were true for one group but not the other; (2) errors in the interpretation of the significance of a relationship. It was pointed out that these errors probably represent general difficulties in the analysis of data from psychiatric studies.

Acknowledgements-This work was supported by career development award 5-K3-MH-9403 and research grant MH-08592 from the National Institute of Mental Health. I would like to thank Dr. J. E. K. SMrTH and Mr. Paul Isaac for statistical advice, Mr. Charles Stallman for technical assistance, and Mrs. Diane RAY for faithful secretarial services.

\section{REFERENCES}

1. Blum, R. H. Case identification in psychiatric epidemiology: Methods and problems. Milbank meml Fund q. Bull. 40, 253, 1962.

2. Cronbach, L. J. and Meehl, P. E. Construct validity in psychological tests. Psychol. Bull. 52, $281,1955$.

3. KETY, S. S. Biochemical theories of schizophrenia. Science 129, 1528, 1959.

4. Dureli, J. and Schildkraut, J. J. Biochemical studies of the schizophrenic and affective disorders. In American Handbook of Psychiatry, Vol. III, ARIET, S. (Editor), p. 423, Basic Books, New York, 1966.

5. Blumenthal, M. D. Mental illness in parents of phenylketonuric children. J. Psychiat. Res. 5, 59, 1967.

6. Gurin, G., Veroff, J. and Feld, S. Americans View Their Mental Health. Basic Books, New York, 1960. 
7. LaNGNER, T. S. A twenty-two item screening score of psychiatric symptoms indicating impairment. J. Hlth. Hum. Behav. 3, 269, 1963.

8. Manis, J. G., Brawer, M. J., HUNT, C. L. and KerCher, L. C. Validating a mental health scale. Am. Sociol. Rev. 28, 108, 1963.

9. HAll, C. E. and Cramer, E. M. A general purpose program to compute multivariate analysis of variance on an IBM 7090 computer. George Washington University Biometric Laboratory, Washington, 1960.

10. HaYs, W. L. Statistics for Psychologists. Holt, Rinehart \& Winston, New York, 1963.

11. Wittenborn, J. R. and Smith, J. B. K. A comparison of psychotic dimensions in male and female hospital patients. J. nerv. ment. Dis. 138, 375, 1964.

12. WittenboRn, J. R. Psychotic dimensions in male and female hospital patients: Principal component analysis. J. nerv. ment. Dis. 138, 460, 1964.

13. Leighton, D. C., Harding, J. S., Macklin, D. B., Macmillan, A. M. and Leighton, A. H. The Character of Danger, Vol. III, The Stirling County Study of Psychiatric Disorder and Sociocultural Environment, Basic Books, New York, 1963. 